\title{
Evaluating User Experience of a Mobile Health Application Halodoc using User Experience Questionnaire and Usability Testing
}

\author{
Mochammad Aldi Kushendriawan * \\ Faculty of Computer Science \\ Universitas Indonesia \\ Kampus UI Depok, Jawa Barat, 16424 \\ mochammadaldik@gmail.com
}

Panca O. Hadi Putra

Faculty of Computer Science

Universitas Indonesia

Kampus UI Depok, Jawa Barat, 16424

hadiputra@cs.ui.ac.id

\author{
Harry B. Santoso \\ Faculty of Computer Science \\ Universitas Indonesia \\ Kampus UI Depok, Jawa Barat, 16424 \\ harrybs@cs.ui.ac.id
}

Martin Schrepp

SAP SE, Cloud Platform User Experience

Walldorf, Germany

martin.schrepp@sap.com

\begin{abstract}
This paper aims to evaluate the user experience of a mobile health application called Halodoc to keep the user using the application and keep from losing a potential source of revenue for Halodoc. Halodoc is one of the companies that use the internet to provide health services for its users. Halodoc has services such as features for consultation with doctors, online medicine purchases, and hospital appointments. Halodoc's vision is to simplifying healthcare, but there are still many complaints and negative reviews about Halodoc on Google play store and Apple store about the usability. This paper uses a mixed-method approach using User Experience Questionnaire (UEQ) and Usability Testing. The results of the analysis were used as a reference for making the improvement designs. The results of the

$U E Q$ evaluation showed accordingly to the UEQ benchmark already a good level of UX.

However, the usability test uncovered some concrete areas for improvement.
\end{abstract}

Keywords: Mobile Health (mHealth), Usability Testing, User Experience Questionnaire, User Interface, User Experience.

\section{Introduction}

Computer and internet technology are solutions to many problems and needs related to the effectiveness and efficiency of a procedure or activity. Companies in the health sector started to implement computer and internet technology in their operations, they changed their activities from an offline concept to an online concept (Yani 2018). Halodoc is one of the companies that use the internet to provide health services and medicines for its users, this application operates in Indonesia with a valuation of more than US \$ 65 million (Crunchbase 2020). Halodoc has complete services such as features for consultation with doctors, online medicine purchases, online laboratories, health articles, making hospital appointments, and an assessment feature for COVID-19. Halodoc is available for Android and iOS, it

\footnotetext{
${ }^{*}$ Corresponding Author with contact details email address and full postal address
} 
has a website that can be used to run its features and have two language can be used, English and Indonesian, depends on the language setting on the users' phone. Halodoc also collaborates with pharmacies, hospitals, medicine distributors, specialist doctors, nurses, and medical equipment suppliers to support the 'Health Store (Toko Kesehatan)' feature. This service helps users to buy medicines or medical devices or household health supplies (Halodoc 2021).

Halodoc offers simplified healthcare to millions of people in Indonesia via the internet. Halodoc's main service is to provide easy access to health through an online application and simplifying healthcare, especially in Indonesia. Halodoc already partnership with more than 20 thousand doctors and more than 4 thousand pharmacies in Indonesia. Meanwhile, in terms of users, Halodoc claims that there are around 18 million active users using their platform, but it is still not enough to achieve their goals to simplified healthcare to millions of people in Indonesia via the internet, they have intention to fix things that make health services have a long waiting time; such as documentations, administrative costs, and matters relating to other medical services (Isna 2020). The number of users, growth of the user base, and number of transactions in the application are the main factor for Halodoc to keep their business. Without users and transaction activities in the application, the company will be hampered to do their activities and will lose potential sources of income. Initial observations were made on user reviews on Google Playstore and Apple Store, there are still many users who give a one-star rating with negative reviews. Incomplete pharmaceutical information, pharmacy supply that is too far from the user's location causing long delivery times, and unclear price information are the negative reviews on Halodoc application that can make the application not being able to meet user expectations to provide health services from Halodoc.

The World Health Organization (WHO) explains that health facilities in the form of technology (mHealth) need to carry out continuous evaluations to increase their effectiveness, efficiency, and user satisfaction (World Health Organization 2011). The term "health technologies" refers to the application of organized knowledge and skills in the form of devices, medicines, vaccines, procedures, and systems developed to solve a health problem and improve quality of life (World Health Organization 2011). Perception of ease of use of applications can influence a person to use health applications (Zhao et al. 2018).

The ISO standard ISO 9241-11: 2018 refers to usability testing as a method to improve the quality of a product concerning effectiveness, efficiency, and user satisfaction. Research by Hinchliffe and Mummery in 2014 examined usability techniques for improving a health promotion website (Hinchliffe and Mummery 2014). The results showed that usability tests can identify improvements from the user's point of view and can be used for the redesign of the site. Meanwhile, to measure the experience felt by users can use the quantitative method of the User Experience Questionnaire (UEQ). UEQ is a method that is easy to apply, valid, and reliable to complement data from other evaluations with a subjective quality assessment (Laugwitz et al. 2008). From the research conducted by Arefe Heshmati et all, the UEQ questionnaire is free and possible to use in all medical informatics applications (Heshmati et al. 2021), it means UEQ can be applied on mHealth to measure the UX score. Based on the previous research, this research can contribute by combining the two methods used to solve problems of effectiveness, efficiency, and user satisfaction, UEQ is used for quantitative methods and usability testing for qualitative methods, so that the results of these two methods are expected to enrich the results of this research.

Based on user complaints through reviews on the Google Playstore and Apple Store regarding the Halodoc application, evaluation of the application and user experience needs to be done regularly so that Halodoc does not lose users and their potential source of income, and can meet Halodoc's goals to facilitate access to health for the Indonesian people. This study involved Halodoc users as respondents, especially users of the health store feature to buy health products in Halodoc. The purpose of this study is to analyze and evaluate the user experience of the Halodoc application based on UEQ and usability factors. This study also seeks to provide recommendations and suggestions for improving the appearance of the Halodoc application based on the results of the UEQ evaluation and Usability Testing. 


\section{Literature Review}

\section{Mobile Health (mHealth) Technology}

mHealth is a broad label for a variety of services, and technologies supported by mobile devices, such as smartphones, patient monitoring devices, personal digital assistants, and other wireless devices to improve behavior, health quality, and individual well-being (Lucivero and Jongsma 2018). There are many wearable devices available in the market with apps that can record body movements, generate charts of daily calorie consumption or exercise, and provide health advice and self-management tools for chronic patients, as well as healthcare providers (Lucivero and Jongsma 2018). The use of mobile health information and sensing technology (mHealth) has the potential to reduce health care costs and improve health data logging. These technologies can support ongoing health monitoring at both the individual and population level, encourage healthy behaviors to prevent or reduce health problems, support the self-management of chronic disease patients, increase provider knowledge, reduce the number of health service visits, and provide personalized services. mHealth also accommodates localization of health services and on-demand interventions in ways previously unimaginable (Krishna et al. 2009).

\section{Halodoc}

Halodoc is an application and website from Indonesia that offers medical services and equipment. Halodoc application already have 5,000,000+ installs in Google Play Store with almost 300,000 reviews and 131,200 reviews on the App Store in April 2021, with that much of downloads, Halodoc has 18 million monthly active users (Silviana 2020). With the aim of facilitating the needs of a healthcare platform in Indonesia by connecting patients with licensed doctors, insurance companies, laboratories, and pharmaceutical installations into an application (Halodoc 2021). Halodoc has several features and services that accommodate user needs:

1. Consultation with a doctor; facilitating Halodoc partner doctors to interact with users via video calls and chat which can be accessed via applications and websites.

2. Buying medicines; connected to the GOJEK (ride-hailing application) as a third party that delivers orders for medicines with doctor's prescription, vitamins, and non-medicated medical devices, healthy food and non-medicinal drinks to users.

3. Hospital features; helps to search for the hospital according to user requirements.

4. Lab inspection features; facilitate laboratory examinations for users who are unable to come directly to the laboratory where phlebotomists (patient blood specimen collectors) work in the laboratory (Halodoc 2021).

5. Health Shop Features; provide medical equipment and other needs related to health.

\section{Usability}

The international norm International Organization for Standardization (ISO) namely ISO 9241-110: 2006 defines the usability of a product as the extent to which a product can be used by specified users to achieve specified goals with effectiveness, efficiency, and satisfaction in a specified context of use.

According to the ISO 9241-110: 2006, effectiveness means that users can achieve their goals with the product accurately and completely, efficiency means that achieving the goals is possible with reasonable effort, and satisfaction describes the feeling that using the product is comfortable and pleasant. To specify these concepts in more detail, the norm defines in addition seven dialog principles. These dialog principles specify properties of a user's interaction with a system that is beneficial to complete tasks, for example, error tolerance or suitability for learning.

Usability accordingly to this definition sets a strong focus on solving tasks or reaching goals with the help of a product or system. Usability on a system is very important so that the system can continue to be used by users. Users will experience the best when using a system that has high usability (Nielsen 2019). 


\section{User Experience}

In our modern competitive environment, offering good usability is no longer sufficient to be successful. For most activities, there are several products available that have similar functionality and similar levels of usability. Thus, to be better than the competition, other interaction qualities must be considered as well. A well-known statement of Don Norman, an academic in cognitive science, design and usability engineering and a former vice president of Apple Inc. who is also the initiator of user-centered design, is "If it doesn 't feel right, who cares if it works?" (Norman 2003).

This statement covers the idea that it is important to care also for interaction qualities that go beyond pure usability, i.e., to consider aspects of the interaction with a product that does not relate to the pure tasks or goals of a user. This idea is also covered in ISO 9241-210: 2019 which defines user experience (short UX) as a person's perceptions and responses that result from the use or anticipated use of a product, system, or service.

Thus, similar to the definition of usability, the user experience depends on user group and context of use. But there are several important differences to the definition of usability. User experience is a completely subjective quality. In the center of the definition is the impression of the user. Thus, the researchers must ask the user about his or her subjective impression concerning his or her interactions with the product to measure UX. Another important difference is that user experience is not only influenced by the actual use of the system. The concept also covers the time before the user uses the product (anticipated use) (Hornbæk and Hertzum 2017).

For a UX designer who wants to know what to do to create a good UX for a product or for a researcher who asks how to measure UX the ISO 9241-210: 2019 definition is not very concrete. Therefore, alternative approaches to specifying user experience have been formulated. For example, Sharp et al. (2019) distinguish between two types of product qualities related to user experience:

- Usability goals: Qualities of an interaction that are related to the tasks that users need to complete to reach their goals. They correspond to the classical definition of usability. Examples are efficiency, learnability, dependability, or adaptability to name just a few.

- User Experience Goals: These are qualities of an interaction that are related to the subjective impression concerning the overall interaction with the product, for example, stimulation (fun of use), novelty, or aesthetic appeal of the user interface. They are not related to working on tasks (Sharp et al. 2019).

\section{User Experience Questionnaire}

The User Experience Questionnaire (UEQ) is based on the idea that UX can be measured by considering usability goals and user experience goals. The questionnaire was constructed empirically and 6 scales that represent the most important UX aspects for a larger set of products resulted from the construction (Laugwitz et al. 2008).

The items of the UEQ are semantic differentials with a 7-point answer scale. They consist of a pair of terms with opposite meanings that span a sematic dimension. An example for an item representing the scale stimulation is:

$$
\text { boring o o o o o o o exciting }
$$

The 6 scales and the corresponding items are:

1. Attractiveness: User's general impression of the product, do they like it or not. Items: annoying/enjoyable, good/bad, unlikable/pleasing, unpleasant/pleasant, attractive/unattractive, friendly/unfriendly.

2. Efficiency: User's impression that reaching goals using the product is quick and efficient, the organization of the interface is clear. Items: fast/slow, inefficient/efficient, impractical/practical, organized/cluttered.

3. Perspicuity: User's impression concerning ease of understanding how to use the product. Items: not understandable/understandable, easy to learn/difficult to learn, complicated/easy, clear/confusing. 
4. Dependability: User's feelings about safety and controllability of the interaction with the product. Items: unpredictable/predictable, obstructive/supportive, secure/not secure, meets expectations/does not meet expectations.

5. Stimulation: User's impression that it is interesting and fun to use the product. Items: valuable/inferior, boring/exiting, not interesting/interesting, motivating/demotivating.

6. Novelty: User's impression that product design is innovative, creative, and catches user's attention. Items: creative/dull, inventive/conventional, usual/leading edge, conservative/innovative.

Efficiency, Perspicuity, and Dependability are task-related UX aspects (usability goals). Stimulation and Novelty are non-task-related UX aspects (user experience goals). Attractiveness is a pure valence dimension, and it is assumed that the rating concerning this aspect is influenced by the task-related and non-task-related aspects.

The questionnaire format supports participants to immediately express feelings, impressions, and attitudes that appear when using a product. Filling out the questionnaire does not require too much effort from the participants, so the UEQ can be used as an online questionnaire. The reliability and validity of the UEQ was investigated in several studies; see Lauwitz et al. (2008) for details.

Additional information concerning the UEQ can be seen at www.ueq-online.org. This site allows also to download of the handbook, a data analysis tool, and various translations of the questionnaire.

\section{Methodology}

\section{Research Design}

This study uses a mixed-method approach, where the research uses quantitative and qualitative analysis simultaneously. Referring to Creswell in Ishtiaq research, the quantitative approach is a technique of analyzing and collecting data through predetermined standardized research tools and producing empirical data in the form of a certain number of scale scores (Ishtiaq 2019). In our study, we use the User Experience Questionnaire to collect empirical data concerning Halodoc. Meanwhile, in a qualitative approach to analyzing non-numerical data, the analysis is carried out on the results of usability testing on design alternatives. Such a qualitative method can produce more detailed suggestions for improvements and usability tests and questionnaires are a good method combination because the strengths of both methods complement each other well.

\section{Data Collection Procedures, Population and Sample}

Respondents in this study were users of the Halodoc application who had already used and transacted at Halodoc at least once so that it was in line with the initial objectives of the study, namely evaluating the user experience of the Halodoc application. In accordance with the UEQ handbook, there should be at least 20-30 respondents in order to get reliable results (Schrepp et al. 2014). The UEQ questionnaire was given to selected respondents using a purposive sampling method. Data collection was disseminated through social media Instagram, Twitter, and LinkedIn by making announcements regarding the link to filling out the research questionnaire that was linked to the UEQ questionnaire link. We obtained 202 responses, after the data was cleaned by remove duplicates and remove the data that does not match the criteria, we got 96 respondents. Data collection was carried out from November 14, 2020 to November 18, 2020.

To get the best result to know the usability problems, usability testing needs to conduct with 3-5 respondents (Nielsen 2019). Three respondents are recruited in this usability testing that focused on the Halodoc users who ever use Halodoc to buy health products before. The respondents are recruited from the UEQ respondents who are willing to participate in usability testing and eligible for the requirements. Usability testing in this study will be carried out remotely, the findings to be captured in this study are the extent to which the respondent succeeded in working on each task, the problems faced by the respondent, application operation errors, comments, and suggestions for improvement designs. Remote usability testing uses the Zoom application, and the scenarios that will be used in this usability testing are: 
"You are doing an activity and feel a sudden headache. You are planning to buy one strip of Panadol headache relievers. Please use Halodoc to buy the medicine."

In this testing, the researcher waiting until the session is complete and then asking questions about the participant's thoughts and actions. The researcher takes notes and follows up with additional questions about their task and asking about suggestions at the end of the session to not interfere with usability metrics. After that, the answer will be coded to clean the data and differentiate every answer or give the same code if the answer are similar. "KUT" words is used to a code name that can can be seen on the Table 1.

For data collection purposes, task scenarios will be needed to guide users in running the application, as well as an instrument to measure the level of effectiveness and efficiency of using the application. Task scenarios are a collection of tasks that must be completed by respondents when using the application (Nurhadryani et al. 2013).

\section{Data Analysis}

User research is conducted to find information based on the real situation of Halodoc users, identify needs, the context of use, and specific user needs. Determination of problems and objectives is carried out by observing problems around them, such as user complaints regarding applications used on the application store platform, conducting interviews with Halodoc, and conducting small talk with users of the Halodoc application regarding the difficulties faced. The UX assessment of the Halodoc application in version 8.0 is to find out the UX value of the Halodoc application, especially the Health Shop feature to buy medicines, then analyze what factors can make the UX value in the Halodoc application increase, the results of this questionnaire will become a reference for making usability testing scenarios that will be done at a later stage.

The instrument of quantitative research is a questionnaire that refers to the UEQ guidebook, using a semantic differential questionnaire 1 to 7 with Indonesian language items (Santoso et al. 2016). The application of this questionnaire uses google form and is distributed to respondents. In this questionnaire, apart from the UEQ items, the researcher also added a validation question to validate that respondents were actually Halodoc users, besides that, they also added personal data questions to see the distribution of the questionnaire and demographics can be made from respondents' answers.

Usability testing tries to find an application usage flow or application interface that does not match a good user experience. Participants in the implementation of usability testing are users of the 'Toko Kesehatan' feature. The ' Toko Kesehatan' feature on the Halodoc application enables to buy health products. Then to determine the usability problems, the best result is to experiment with 3-5 respondents (Nielsen 2019). Usability testing was chosen because it would be useful when combined with a survey or quantitative questionnaire, to increase the validity of the data because it clarified the specifics raised in the survey or questionnaire (Zaphiris et al. 2018).

Initial data processing was carried out regarding UEQ data, at this stage, processing was carried out by following the tools provided by the previous UEQ researchers in the form of excel sheets. In this process, the results obtained from the UEQ questionnaire are used, then the data processing of usability testing results is carried out which is also done in parallel with data processing from the UEQ questionnaire. The process of designing an alternative prototype of the Halodoc interaction design is based on the analysis of usability findings. The prototype produced in this research is made with the collaborative design tool called Figma to make it high-fidelity. In the final section, conclusions are made after the results of the initial and final UX values are compared. After that, it can be seen if the design needs improvement and enters the evaluation stage again, or it can immediately enter the stage of achieving satisfaction.

\section{Results}

\section{Evaluation Results using the User Experience Questionnaire}


Measurement of user experience in the Halodoc application design with UEQ has carried out 96 respondents who entered the criteria with the demographics of 32 male respondents and 64 female respondents, the majority were 20-29 years old as many as 88 respondents, 6 respondents from 30-39 years old, 1 respondent from 40-49 years old, and 1 respondent from 50-59 years old. Meanwhile, from the domicile, there were 84 respondents from Jabodetabek, 2 respondents from outside the Java island, and 10 respondents from the Java island other than the following cities: Jakarta, Bogor, Depok, Tangerang, and Bekasi (Greater Jakarta).

The overall results of the Halodoc UEQ scale are depicted in Figure 1 and 2. The value of each UEQ item can be seen in Figure 1, where the average on the Attractiveness scale is 1,778; Perspicuity 1,810; Efficiency 1.818; Dependability 1,622; Stimulation 1,570; and Novelty 1,211.

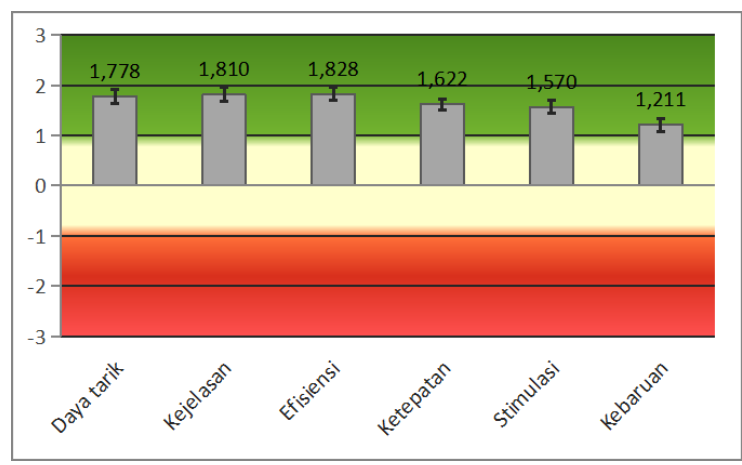

Figure 1. Average UEQ scale values of the Halodoc application design

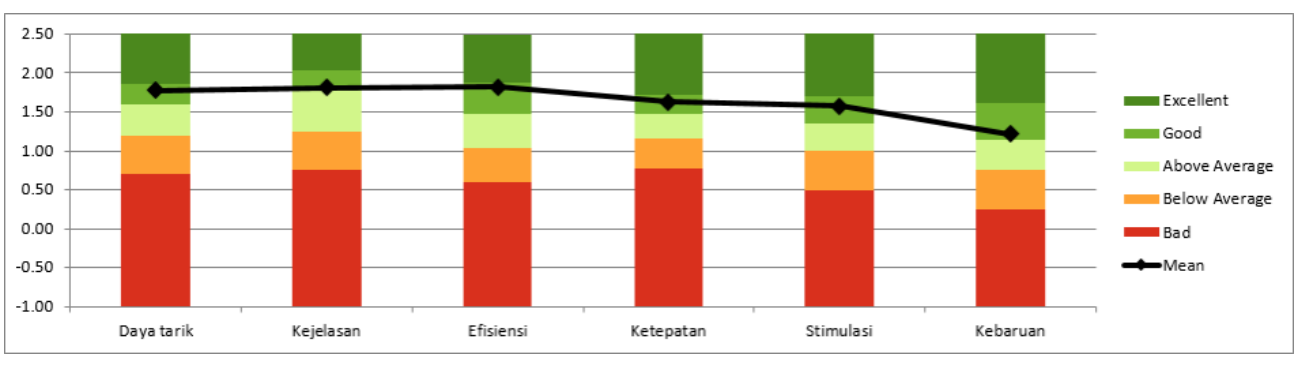

Figure 2. UEQ benchmark diagram on the Halodoc application

Figure 1 shows the results of the questionnaire responses on the Halodoc application are all positive user experience (according to the handbook a value falls into the positive range if it is $>0.8$ ). This section will be evaluated for the part that will increase the value of the user experience in the next design improvement.

Based on the UEQ benchmark results diagram, the Halodoc application is included in the "good" category. The benchmark contains data from more than 400 different evaluations of products with the UEQ. A value is in the Good category if it is amongst the $25 \%$ best results from this benchmark data set. Thus, according to the UEQ, the overall quality of the Halodoc application is already high. However, none of the scale values falls into the Excellent category that corresponds to the $10 \%$ best results, thus there is still room for improvement. Therefore, to find out the focus of improvements caused by these deficiencies, an additional usability testing method was carried out.

\section{Evaluation Results using Usability Testing}

Based on the evaluation results, the main obstacle of the Halodoc application for purchasing health products is the lack of certainty or clarity regarding medicine purchases, such as information on selected pharmacies, medicine availability, uncertain medicine price information, and a lack of flexible search features. This is supported by the results of the evaluation which state that most respondents expect to 
develop a search feature that initially can only take the product name as input, to be developed into several input options such as medicine type, disease name, medicine type filter feature, pharmacy distance, and price. The search button, that is too small, should be enlarged. The results of the conclusions of this usability testing analysis can be seen in Table 1 .

Table 1. Conclusion of Usability Testing Analysis

\begin{tabular}{|c|l|}
\hline Code & \multicolumn{1}{c|}{ Usability Testing Analysis Conclusion } \\
\hline KUT1 & Medicine prices are uncertain, can be expensive or cheap \\
\hline KUT2 & Search feature that is not visible on the home and on the medicine list \\
\hline KUT3 & Not knowing which pharmacy to buy, worried about the delivery time \\
\hline KUT4 & $\begin{array}{l}\text { Searching for medicines manually without a search feature makes it difficult for } \\
\text { users because there is no sort or filter feature like in e-commerce }\end{array}$ \\
\hline KUT5 & There are no alternative solutions when medicines are not available \\
\hline KUT6 & The writing on the button goes to pay which creates a misperception \\
\hline
\end{tabular}

\section{Discussion}

\section{Previous Design of Halodoc Mobile Application}

The initial view of the Halodoc application, the home display of the Halodoc application can be seen in Figure 3. On the home screen, there is information about the username that is logged in, current location, features found on Halodoc (Chat with Doctors, Health Stores, and Make Hospital Appointments), other services, and health articles.

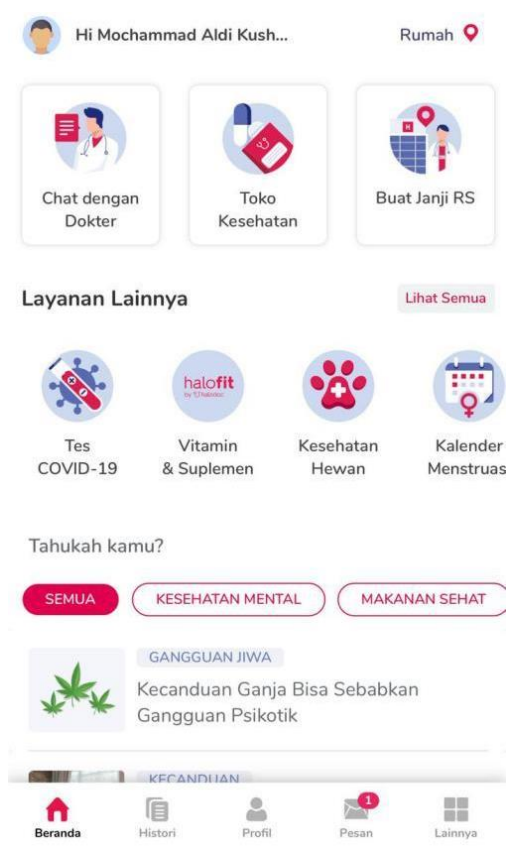

Figure 3. Halodoc Home Display

After clicking the 'Toko Kesehatan' feature, the initial health shop feature menu will appear which can be seen in Figure 4. In the display, there is the current location, a transaction history symbol, a search feature to upload prescription medicines, a choice of disease categories, and a choice of pharmacies that work with Halodoc. To order your medicine from this screen, you can click on the choice of health products or selected pharmacies, then the screen will display medicine options selected according to the selected product category, as shown in Figure 5. On this screen, there are products with sponsor labels and products that are not sponsored products, there is also a back button on the top left of the screen, and a search button on the top right of the screen.

After selecting a medicine that is on the product category menu display or the selected medicine, the system will automatically display the search for the nearest pharmacy. After successfully getting the 
pharmacy of choice automatically, the user will be immediately directed to the cart menu display as shown in Figure 6, the user will get information on the medicine image, medicine label, medicine name, price and quantity ordered, upload prescription feature, delivery address, notes, total price, the next button, and the estimated time of delivery until the medicine is received by the user.

Users can also change the shipping address by clicking the red "change" button, and after clicking the display will immediately appear selecting the address that is on. In the display of the payment options menu that can be accessed when the user clicks the "next" button on the basket view, there is a medicine purchase option for whom, details of prices from medicine prices to Halodoc delivery service prices, there is a section for filling in promo codes, and of course there is a choice of the available payment methods as shown in Figure 7. If the user has selected the desired payment method, the pay \& message button will turn red, and when the button is clicked, the user will immediately be directed to the successful payment display if the payment is successful.

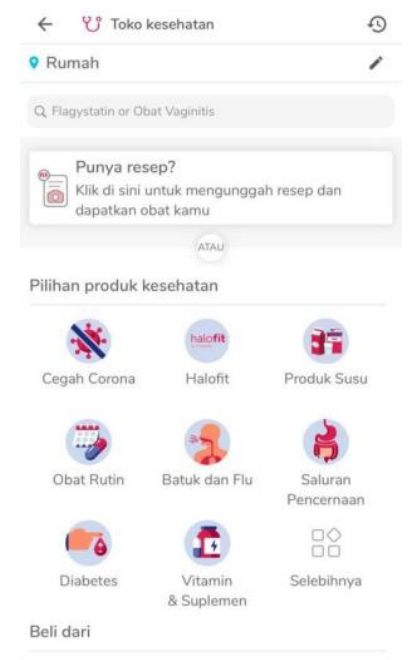

Figure 4. Halodoc 'Toko Kesehatan' Feature Menu

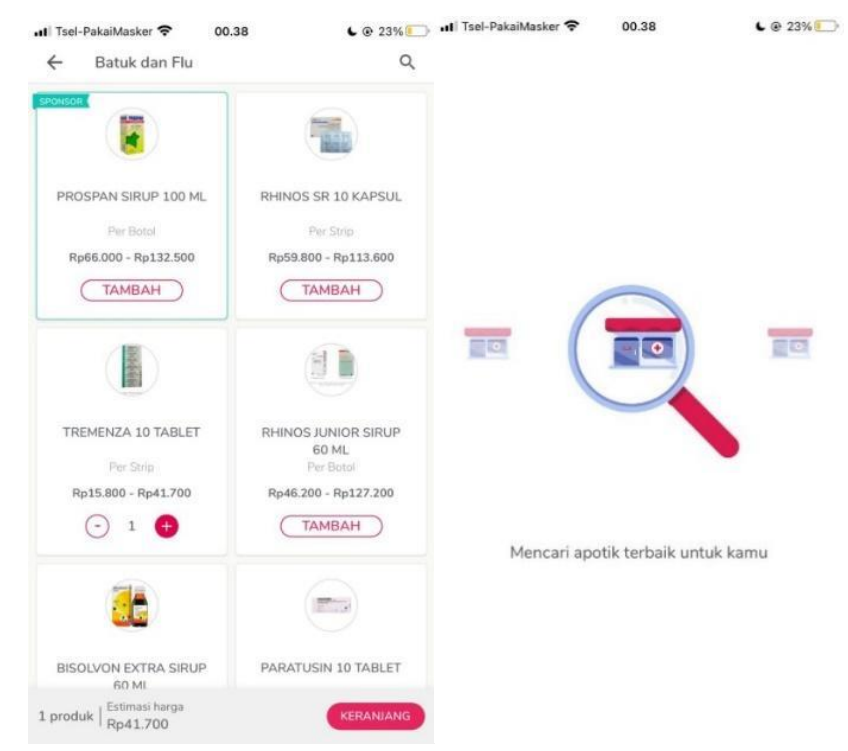

Figure 5. Display of Medicine Category Menu and Pharmacy Search 


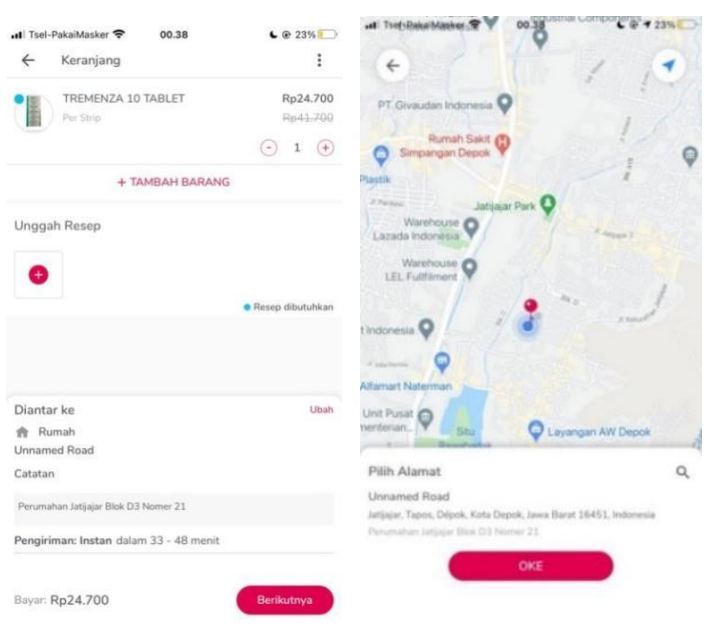

Figure 6. Basket Menu Display and Address Selection

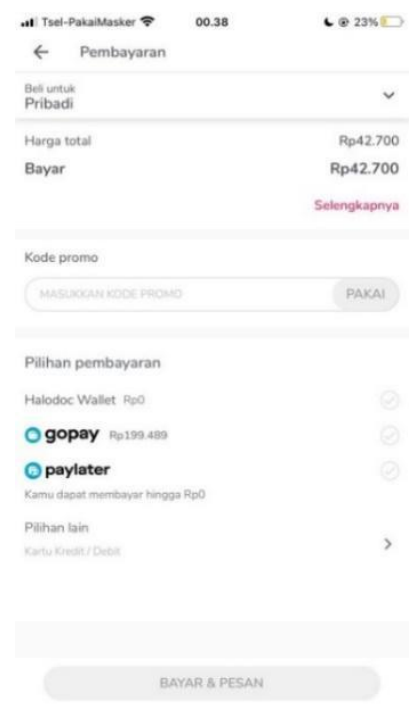

Figure 7. Payment Options Menu Display

\section{Design Improvement}

The improvement in this study is in accordance with the results of the UEQ and usability testing, which can be seen in the previous section. The design improvements will focus on certainty or clarity regarding the transaction, whether it is clarity in delivery, delivery method, and delivery time. There are four display screens that are design improvements. Several displays are intentionally blurred because currently the displays are being considered by Halodoc to be implemented.

1. Home Display improvements: the first recommendation focuses on the home display regarding changes to the search feature that is exchanged for a position with the upload recipe button, this is related to the results of usability testing analysis with the KUT2 code regarding the less visible search feature, while this feature is very useful for users to select the product they need as shown in Figure 8.

2. Location improvement design, further improvements are made by setting the user's location at the beginning of the phase, when on the home screen, this is intended to encourage users to fill in the shipping address first to avoid address delivery errors, and to help the Halodoc system to determine the exact price of medicines available at the closest location to the user, as well as seeing the availability of the product you are looking for, this is related to the results of usability testing analysis with the KUT1 code as shown in Figure 9. 


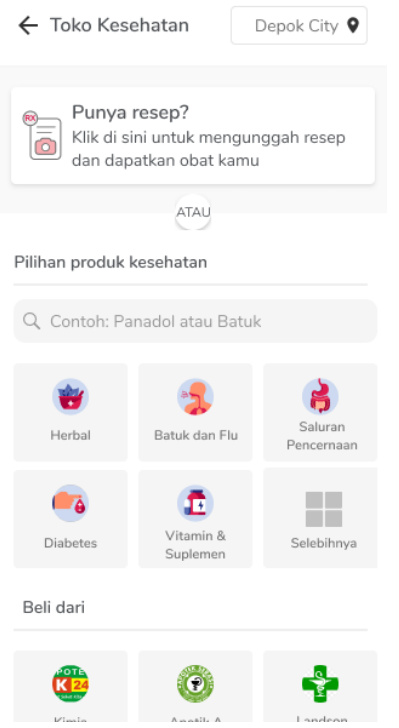

Figure 8. Home display improvements

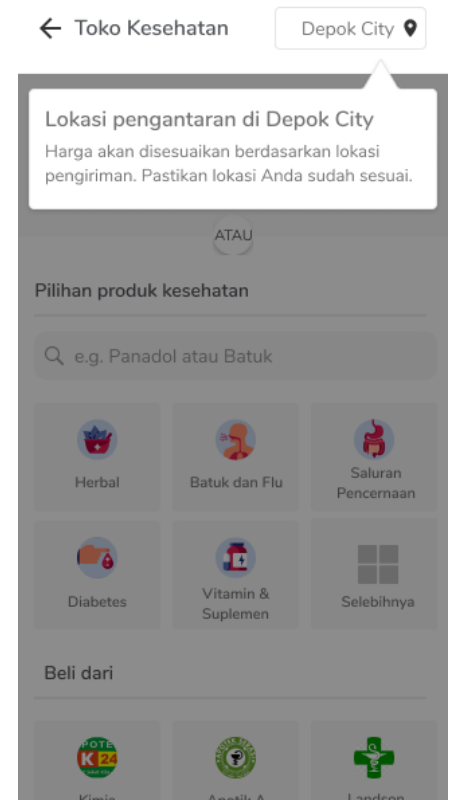

Figure 9. Improvements to the Display of Delivery Location Options

3. Health Product List improvement, further improvements to the display of health product lists, in this case in the form of medicines. Improvements are made to the price display, which if it has been set at the nearest pharmacy, the price will be adjusted and can display the appropriate price because it has filled in the shipping address at this stage, as seen in Figure 10. In the upper right corner of the display also remains the address option. Then according to the KUT4 code, the sort and filter features were added to help make it easier for users to use the application to search for health products.

4. The addition of a Toko Kesehatan selection feature, further improvements to the addition of a choice of delivery selection features that are more displayed so that users are more aware of adjustable delivery times, it is hoped that users will no longer feel worried about uncertain delivery times and confusion when not available, also it can be an alternative solution when the medicine cannot be purchased. This is related to the results of usability testing analysis with the KUT3 and KUT5 codes and can be seen in Figure 11. 


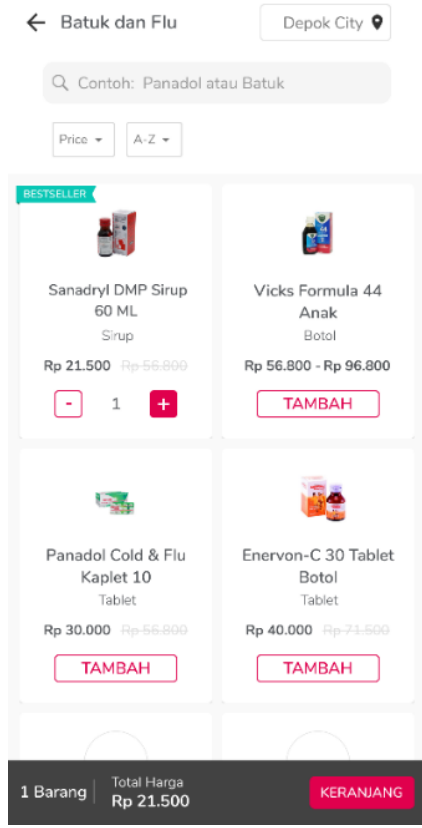

Figure 10. Improvements to the Health Product List Display

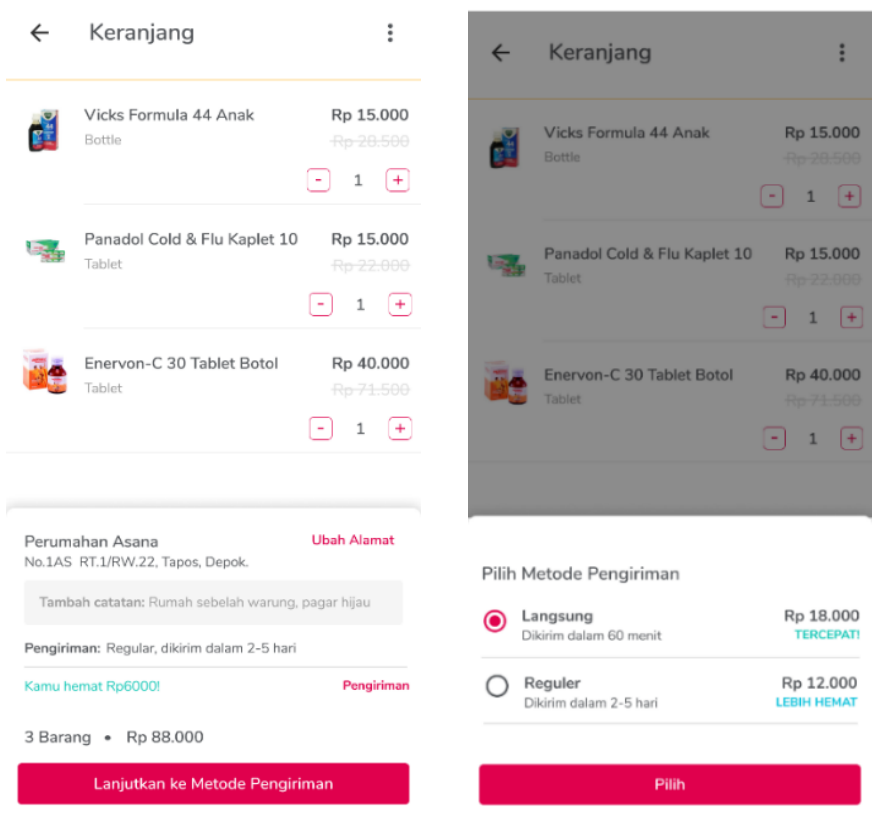

Figure 11. Improved Shopping Cart \& Shipping Method Selection Display Design

\section{Conclusion}

The results of the analysis using the UEQ method obtained an average scale of Attractiveness of 1.778; Perspicuity 1.810; Efficiency 1.818; Dependability 1.622; Stimulation 1.570; and Novelty 1.211. These results explain that the Halodoc application according to the UEQ scale has a positive user experience value because all scales show an average value greater than 0.8 . The comparison to the benchmark showed that all scale values fall into the category Good (best 25\%), but not into the category Excellent (best 10\%). Meanwhile, another finding stated that there were complaints in the questionnaire related to pharmacies that were obtained far from the delivery location, causing delivery to take more time. Based on the results of the evaluation analysis using the usability testing method, the main obstacle of the Halodoc application for purchasing health products is the lack of certainty or clarity regarding medicine purchases, such as information on selected pharmacies, availability of medicines, uncertain medicine price information, and less flexible search features. This is supported by the results of the 
evaluation which state that most respondents expect to develop a search feature that initially can only take product names as input, to be developed into several input options such as types of medicines, prices, names of diseases, and requires additional features of pharmacy distance and options delivery. On the other hand, improvements to the button size need to be done, some button display sizes are too small.

This study shows the importance of involving end-users in the observation. UEQ and usability testing will get the recommendation of the solution based on the observation. As a result, it is recommended to use the design alternatives to help Halodoc to achieve their goals of simplifying healthcare for Indonesia and can increase the Halodoc application's user experience score by implementing the suggestion design based on this research.

We acknowledge this research has limitations. Only three participants were involved during the UT. This causes the research findings can be more improved in the number of participants to enrich the data and suggestions. Moreover, this study relies on the survey and user testing as data collection methods. For future research, expected to get more participants for data collections and add UEQ data collection for the new improved design suggestions to get the UX score, so it can be compared to the current design UX score and enrich the results.

\section{Acknowledgement}

This research was supported by Hibah Publikasi Terindeks Internasional (PUTI) Q2 2020 at Universitas Indonesia (Number: NKB-4061/UN2.RST/HKP.05.00/ 2020).

\section{References}

Crunchbase. 2020. "Halodoc - Crunchbase Company Profile \& Funding." (https://www.crunchbase.com/organization/halodoc, accessed April 22, 2021).

Halodoc. 2021. "Join Us - Career | Halodoc.” (https://www.halodoc.com/career, accessed April 21, 2021).

Heshmati, A., Moftian, N., Rezaei-Hachesu, P., and Samad-Soltani, T. 2021. "Simple and Efficient Measurement of the User Experience in Health Information Systems: A Persian Version," Iranian Journal of Public Health (50:1), Iranian Journal of Public Health, pp. 217-218. (https://doi.org/10.18502/ijph.v50i1.5097).

Hinchliffe, A., and Mummery, W. K. 2014. "Applying Usability Testing Techniques to Improve a Health Promotion Website," Health Promotion Journal of Australia (19:1), Australian Health Promotion Association, pp. 29-35. (https://doi.org/10.1071/he08029).

Hornbæk, K., and Hertzum, M. 2017. "Technology Acceptance and User Experience: A Review of the Experiential Component in HCI," ACM Transactions on Computer-Human Interaction (24:5), Association for Computing Machinery, pp. 1-30. (https://doi.org/10.1145/3127358).

Ishtiaq, M. 2019. "Book Review Creswell, J. W. (2014). Research Design: Qualitative, Quantitative and Mixed Methods Approaches (4th Ed.). Thousand Oaks, CA: Sage," English Language Teaching (12:5), Canadian Center of Science and Education, p. 40. (https://doi.org/10.5539/elt.v12n5p40).

Isna, T. D. 2020. "Startup Story: Halodoc, Hadir Dengan 20 Ribu Dokter Secara Daring." (https://www.wartaekonomi.co.id/read307072/startup-story-halodoc-hadir-dengan-20-ribudokter-secara-daring., accessed April 21, 2021).

ISO 9241-11: 2018. "ISO 9241-11:2018(En), Ergonomics of Human-System Interaction — Part 11: Usability: Definitions and Concepts." (https://www.iso.org/obp/ui/\#iso:std:iso:9241:-11:ed2:v1:en, accessed April 21, 2021).

ISO 9241-110: 2006. "ISO 9241-110:2006(En), Ergonomics of Human-System Interaction — Part 110: Dialogue Principles." (https://www.iso.org/obp/ui/\#iso:std:iso:9241:-110:ed-1:v1:en, accessed April 21, 2021). 
ISO 9241-210: 2019. "ISO - ISO 9241-210:2019 - Ergonomics of Human-System Interaction - Part 210: Human-Centred Design for Interactive Systems." (https://www.iso.org/standard/77520.html, accessed April 21, 2021).

Krishna, S., Boren, S. A., and Balas, E. A. 2009. "Healthcare via Cell Phones: A Systematic Review," Telemedicine and E-Health (15:3), pp. 231-240. (https://doi.org/10.1089/tmj.2008.0099).

Laugwitz, B., Held, T., and Schrepp, M. 2008. "Construction and Evaluation of a User Experience Questionnaire," in Lecture Notes in Computer Science (Including Subseries Lecture Notes in Artificial Intelligence and Lecture Notes in Bioinformatics) (Vol. 5298 LNCS), Springer Verlag, pp. 63-76. (https://doi.org/10.1007/978-3-540-89350-9_6).

Lucivero, F., and Jongsma, K. R. 2018. "A Mobile Revolution for Healthcare? Setting the Agenda for Bioethics," Journal of Medical Ethics (44:10), BMJ Publishing Group, pp. 685-689. (https://doi.org/10.1136/medethics-2017-104741).

Nielsen, J. 2019. "Usability 101: Introduction to Usability." (https://www.nngroup.com/articles/usability-101-introduction-to-usability/, accessed April 21, 2021).

Norman, D. A. 2003. The Design of Everyday Things, Revised And Expanded Edition . (https://mitpress.mit.edu/books/design-everyday-things-revised-and-expanded-edition).

Nurhadryani, Y., Sianturi, S. K., and Hermadi, I. 2013. "Pengujian Usability Untuk Meningkatkan Antarmuka Aplikasi Mobile Usability Testing to Enhance Mobile Application User Interface," Jurnal Ilmu Komputer Agri-Informatika (2:2010), pp. 83-93.

Santoso, H., Schrepp, M., Kartono Isal, R. Y., Yudha Utom, A., and Priyogi, B. 2016. "Measuring the User Experience," The Journal of Educators Online (13:1), Grand Canyon University. (https://doi.org/10.9743/jeo.2016.1.5).

Schrepp, M., Hinderks, A., and Thomaschewski, J. 2014. "Applying the User Experience Questionnaire (UEQ) in Different Evaluation Scenarios," in Lecture Notes in Computer Science (Including Subseries Lecture Notes in Artificial Intelligence and Lecture Notes in Bioinformatics) (Vol. 8517 LNCS), Springer Verlag, pp. 383-392. (https://doi.org/10.1007/978-3-319-07668-3_37).

Sharp, H., Preece, J., and Rogers, Y. 2019. Interaction Design: Beyond Human-Computer Interaction (5th Edition), (5th editio.). (http://graphics.stanford.edu/projects/iwork/).

Silviana, C. 2020. "Indonesia's Halodoc Sees Telemedicine Growing Even in Post-COVID Times." (https://www.dealstreetasia.com/stories/halodoc-209641/, accessed April 21, 2021).

World Health Organization. 2011. Based on the Findings of the Second Global Survey on EHealth Global Observatory for EHealth Series-Volume 3 MHealth New Horizons for Health through Mobile Technologies. (http://www.who.int/about/).

Yani, A. 2018. "Pemanfaatan Teknologi Dalam Bidang Kesehatan Masyarakat Utilization of Technology in The Health of Community Health," Artikel XII (8:1). (http://jurnal.unismuhpalu.ac.id/index.php/PJKM).

Zaphiris, P., Dellaporta, A., and Mohamedally, D. 2018. "User Needs Analysis and Evaluation of Portals," in Portals, Facet, pp. 52-62. (https://doi.org/10.29085/9781856049832.007).

Zhao, Y., Ni, Q., and Zhou, R. 2018. "What Factors Influence the Mobile Health Service Adoption? A Meta-Analysis and the Moderating Role of Age," International Journal of Information Management, Elsevier Ltd, pp. 342-350. (https://doi.org/10.1016/j.ijinfomgt.2017.08.006).

\section{How to cite:}

Kushendriawan, A., Santoso, H. B., Putra, P. O. H., and Schrepp, M. 2021. "Evaluating User Experience of a Mobile Health Application 'Halodoc' using User Experience Questionnaire and Usability Testing," Jurnal Sistem Informasi (Journal of Information System) (17:1), pp. 58-71 